\title{
Smart System for Boiler Automation
}

\author{
Rashmi Welekar ${ }^{*}$, Sonal Rajurkar ${ }^{2}$ and Urvashi Kodwani ${ }^{3}$ \\ 1Shri Ramdeobaba College of Engineering and Management, \\ Nagpur, Maharashtra, India, \\ ${ }^{2}$ Vellore Institute of Technology, India, \\ ${ }^{3}$ Barclays Global services Companey Private Ltd.,India.
}

\section{ABSTRACT}

To monitor the health of boiler, various parameters like temperature, pressure, water level indication and water hardness testing are important. By measuring these parameters and comparing it with a reference value one can signify whether the boiler is working properly or not. Because of improper supply of coal and irregular cleaning of boiler the temperature increases and explosion takes place. This research mainly focusses in monitoring the condition of boiler by automating temperature values and generating proper warning and alarm system for the same.

KEY WORDS: INTERNET OF THINGS, BOILER AUTOMATION SYSTEM, TEMPERATURE MONITORING IN BOILER, SENSORS.

\section{INTRODUCTION}

A boiler is an enclosed vessel that is used for combustion purpose and helps in transferring of heat to water till it gets converted to hot steam or water. This steam is then used by the industry for further processes. The problem arises when the temperature and pressure of these boilers exceeds beyond threshold value and they explode. Hence it becomes important to keep a track of temperature and pressure so that boiler explosions are avoided and human lives and damage cost to the industries are reduced. The temperature increases because the amount of coal or burning substance provided is not in proper amount and hence it eventually increases temperature in boiler. Pressure increases if the amount of water in boiler is not present in appropriate quantity and it becomes necessary to keep a track of water level. If some parts of the boiler

\section{ARTICLE INFORMATION}

Received 18th Oct 2020 Accepted after revision 30th Dec 2020 Print ISSN: 0974-6455 Online ISSN: 2321-4007 CODEN: BBRCBA

Thomson Reuters ISI Web of Science Clarivate Analytics USA and Crossref Indexed Journal

\section{Clarivate
Analytics}

NAAS Journal Score 2020 (4.31)

A Society of Science and Nature Publication,

Bhopal India 2020. All rights reserved.

Online Contents Available at: http//www.bbrc.in/

Doi: http://dx.doi.org/10.21786/bbrc/13.14/80 are corroded, then they are not able to withstand the pressure and hence explode. Also, variation in pressure is caused by steam leakage. The pressure level decreases due to steam leakage and hence it becomes necessary to monitor these things.

In literature we studied the root cause of different boiler explosion and also the methods to prevent it. The original burners in the boiler were recently exchanged with low NOx burners and the new burner system was to be proposed. In this journal we got the knowledge about how to improve efficiency of boilers and what are its parameters. As per the recent trends, more priority is given to the energy conversation policies over energy supply policies. The efficient management of process system will result in energy savings, improved process efficiency, lesser maintenance and operating cost, and greater environmental safety. The focus of the present work is to study the effect of system modification for improving energy efficiency. When it comes to performance measurement in any power plant industry, computing boiler efficiency is considered as one of the most important criteria. There are research papers in literature which shows analysis of boiler losses and methods to improve its heat rate accordingly. 
This journal tells us about the description of steam boiler and its related features. The produced steam is supplied to the industrial process work at low pressure in cotton mills. Study of literature helped us to get information of variation of boiler efficiency by increasing excess of air. The main goal of that research study is to highlight the areas with maximum energy losses in any thermal power stations and overcome the issue with flexible solution with the help of energy and energy analysis as the tools. The book helped us to get more knowledge about modern boiler types and its applications in real world scenario. Boilers are generally classified based on their combustion method, applications or on their type of steam/water circulation. This chapter will present mainly water tube boiler types, categorized by their combustion process and application.

This book helped to learn how to conserve energy and use it in economical manner. The aim is to reduce the energy losses in the boiler and to increase its efficiency. The brief introduction of general energy conservation techniques in boilers is presented here. Work in literature also provides information about analysis and performance of high pressure boilers along with its accessories. The main objective of some of the project work is to analyze the efficiency of economizer, super heater $\mathrm{Ct}$ air pre heater by varying the various parameters in boiler section.

\section{METHODOLOGY}

Gas and oil-fired boilers both use controlled fuel combustion to heat water. The primary boiler components involved in this process are the burner, heat exchanger, combustion chamber, and controls. The burner combines the fuel and oxygen together and provides a site for combustion using the ignition system. This process occurs in the combustion chamber and the produced heat is transferred through the heat exchanger to water. The switches control the firing rate of the ignition burner, fuel supply, air supply, exhaust draft, water temperature, vapor pressure and boiler pressure.

Figure 1: Schematic Diagram of Boiler Room

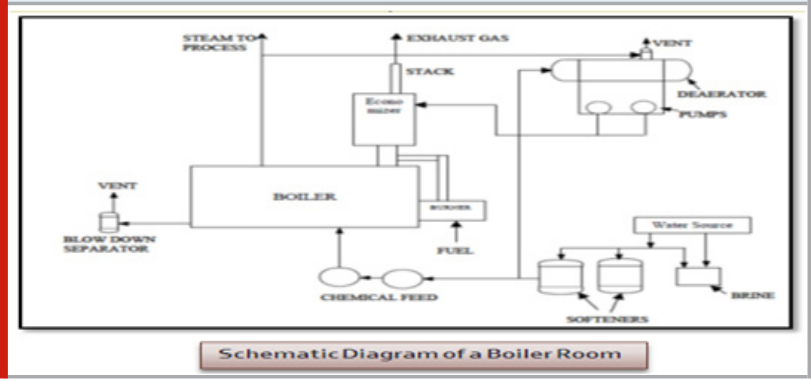

The produced hot water by a boiler is pumped through pipes located at different places in the building and is delivered to the equipment that includes hot water coils in air handling units, service hot water heating equipment and terminal units. The steam generated from the Steam boilers flows from high pressure areas to that of low pressure areas with the help of pumps available.
Now this steam can be used directly by the equipment's for the further process.

The boiler system comprises of: a feed water system, steam system and fuel system. The resultant of conversion of water to steam in boiler is termed as feed water. It maintains the water level in the boiler and takes required actions to meet the steam demand. Various valves are located around the boiler which provide access for maintenance and repair. For safety reasons, the system is fully equipped with safety valves and gauges. Throughout the system, steam pressure is maintained using valves and steam pressure gauges. Other than boiler system there is presence of fuel system which regulates the generation of heat. This system includes all equipment used to provide fuel to generate the necessary heat. The requirement of the equipment in the fuel system is totally dependent on the type of fuel used in the system.

\section{The two sources of feed water are:}

1. Condensate or condensed steam returned from the processes and

2. Makeup water (treated raw water) is exported from outside the boiler. For higher boiler efficiencies, one of the most important part named as economizer preheats the feed water using the waste heat in the flue gas.

Keeping in mind the problems faced by the manufacturing industries like boiler explosion, steam leakage, we proposed a solution that will help in monitoring the system and hence reducing the factory along with human damages. The following figure represents the proposed model. The model comprises of the control panel, boiler, pump, Temperature gauge, Pressure gauge and LCD display. The experimental setup is explained as follows:

Figure 2: Proposed model

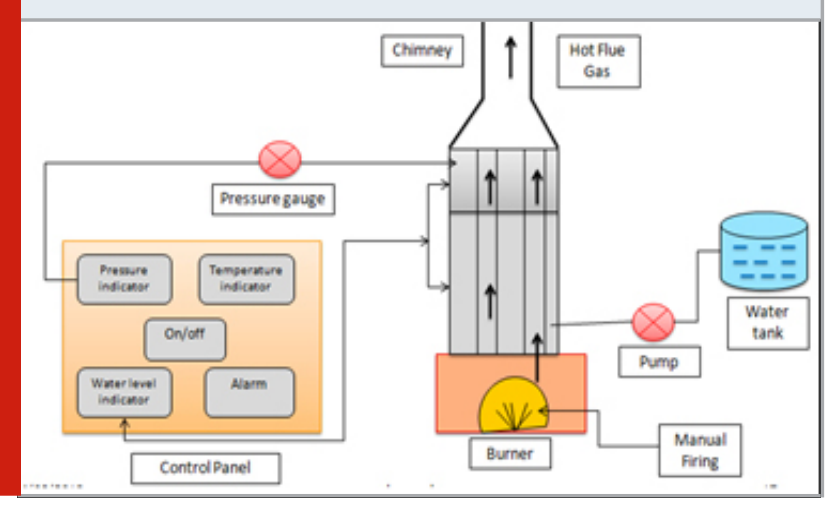

- Control Panel: The control panel consists of pressure and temperature indicator which will indicate the pressure and temperature of boiler. It consists of on/off switch which automatically turns on/off according to water level. Then it has boiler on/off switch through which boiler is operated. It consists of two alarm which will warn if temperature and pressure exceeds a threshold value.

- Boiler: The boiler consists of three parts namely male 
part, female part and economizer. Coal Pieces are inserted inside female part. There are several holes for regulation of air and fire. Water is inserted through valve provided in the male part which surrounds the air tubes. It consists of tubes which regulate steam. Economizer is used in steam power plants to capture the waste heat from boiler stack gases (flue gas) and release those gases via chimney.

- $\quad$ Pump: The pump will regulate water from water tank according to the quantity of water present in the boiler. If water level is below required value, then pump gets on and water is provided to the boiler.

- Gauge: The temperature and pressure gauge will be required to continuously monitor temperature and pressure of the boiler

- LCD Display: LCD display will be provided to show temperature and pressure in the boiler.

\section{RESULTS AND DISCUSSION}

Arduino is used as a main unit, LM35 is used as a monitoring unit and buzzer is used as a warning unit. Measuring the temperature by using two LM35 and comparing the temperature of both $\operatorname{lm} 35$ and display and buzzer is used for warning. The particular range is set by using potentiometer i.e. maximum temperature can be set, if the temperature exceeds than that the buzzer will turned ON else it is OFF. It measures from -10 degree Celsius to +85 degree Celsius for accurate result. The LM35 sensor is used because of its low cost, easy availability, effective working range, accuracy. These two sensors will collect data from their respective surroundings and this data is given to Arduino for processing. Arduino uno is the micro controller used for adding intelligence to the circuit. Arduino UNO is selected because it is cheap, open source programmable micro controller. The two temperatures are then compared and if the surrounding temperature between 30 to 45 degrees then the maximum permutable range of heat given out by compressor should be in the range of 55 to 70 degrees depending on the temperature the indoor unit is set.

Figure 3: Block Diagram

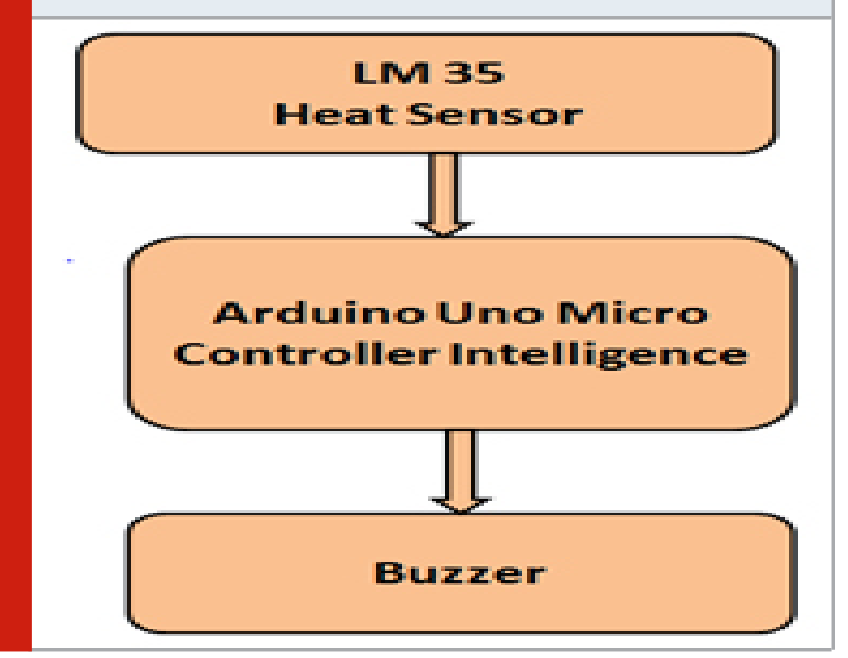

The LM35 is an analog sensor for temperature. This implies that an analog signal is the output of LM35. Analog signals are not explicitly recognized by microcontrollers as their data. Before we can feed it to a microcontroller 's input, we need to convert this analog output signal to digital. We can use an ADC (Analog to Digital Converter) for this reason. We need to use an external ADC to convert the analog output from LM35 to digital if we are using a simple microcontroller like 8051. Then we feed the ADC (converted digital value) output to the 8051 input. But modern day boards like Arduino come with inbuilt ADC. Our Arduino Uno has a 10-bit ADC ( 6 channel) built-in within it. We can use the builtin Arduino ADC to convert the LM35 analog output to digital output. Since Arduino Uno has a 6 channel inbuilt $\mathrm{ADC}$, there are 6 analog input pins numbered from A0 to A5. Connect analog out of LM35 to any of these analog input pins of Arduino. The temperature monitoring system is thus made and tested successfully. It showed the proper temperature variation and warned the user if temperature was about to hit the threshold and when it hits the threshold. Thus it worked successfully.

\section{CONCLUSION}

In boiler monitoring system we have designed a unit to monitor the temperature of boiler. As the temperature or heat is a main parameter which makes any boiler explode hence we have kept track of temperature. As found in research papers there are some standard values of temperature. If the temperature exceeds more than the given threshold value, then boiler tends to explode. One more unit is there in system by which we can set the warning temperature value for boiler output. If temperature exceeds more than a set value it will warn the user of a system by blowing buzzer. This system helps the user to detect a problem so that the boiler is switched off at appropriate time.

\section{ACKNOWLEDGEMENTS}

Numerous individuals have contributed their time and energies in aiding us complete our work magnificently. We express our gratitude to the company Sanket Plants and Equipments Pvt. Ltd and CEO Mr. C.G. Matri for his constant reinforcement and motivation. We are also thankful to Dr. Rupesh Pais, Coordinator-RGSTC-TIFACMSME Program, Dr. M. B. Chandak, Head, Computer Science and Engineering Department and Dr. R. S. Pande, Principal, RCOEM, for their constant support and help which encouraged us a lot in completing this project. And last but not the least we would like to acknowledge our parents, friends, contemporaries and all those people who have directly or indirectly helped us in carrying out our work successfully.

\section{REFERENCES}

Kabir G. Energy Conservation in Boiler, Thapar University. Patiala. 2015

Mohsen D, Hamidreza S. Effect of Operational Parameters on Combustion and Emissions in an 
Industrial Gas Turbine Combustor. Journal of Energy Resources Technology. JERT. Vol. 141.Issue 1. 2018

Parvez M. Steam Boiler. In Al Falah University. Faridabad. September 2017
Sangeeth G , Marathur P. Efficiency Improvement of Boiler. International Research Journal of Engineering and Technology. IRJET. Vol. 02. pp. 265-268. 2015 Sebastian T. Modern Boiler Types and Applications. Helsinki University of Technology. Finland.2015 